\title{
Photocatalytic Degradation of Malachite Green using Undoped and Carbon-Doped Calcium Molybdate Catalysts
}

\author{
H.S. Chawda ${ }^{1, *}$, J. Bhatt ${ }^{1}$, R. Rathore ${ }^{2}$, S.C. Ameta ${ }^{1}$, R. Ameta ${ }^{3}$ \\ ${ }^{1}$ Department of Chemistry, PAHER University, Udaipur - 313 024, Rajasthan, India. \\ ${ }^{2}$ Department of Chemistry, B.N. University, Udaipur - 313 001, Rajasthan, India. \\ ${ }^{3}$ Department of Chemistry, J.R.N. Rajasthan Vidhyapeeth (Deemed to be University), Udaipur - 313 002, Rajasthan, India.
}

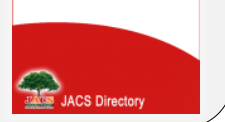

\section{AR T ICLEDETAILS}

\section{Article history:}

Received 30 March 2021

Accepted 10 April 2021

Available online 26 May 2021

\section{Keywords:}

$\mathrm{CaMoO}_{4}$

Photocatalytic Activity

Malachite Green

\begin{abstract}
A B S T R A C T
Calcium molybdates (undoped and carbon-doped) have been used as a photocatalyst for the degradation of malachite green. These have been characterized by different techniques such as FE-SEM, EDX and XRD. The progress of the reaction has been monitored spectrophotometrically. Different rate affecting parameters like $\mathrm{pH}$, concentration of dye, amount of semiconductor and light intensity have been studied and their optimum values obtained are $\mathrm{pH} 9.7$, concentration of malachite green as $5.00 \times 10^{-4} \mathrm{M}, 0.12 \mathrm{~g}$ of $\mathrm{CaMoO}_{4}$ and light intensity as $50.0 \mathrm{mWcm}^{-2}$. A tentative mechanism for the photocatalytic degradation of dye has been proposed, where hydroxyl radical has been observed as an active oxidizing species.
\end{abstract}

\section{Introduction}

Malachite green is used to colour materials such as silk, leather and paper. It is commonly used in aqua culture as a parasiticide and in food, health, textile and other industries. In spite of its uses, this dye has generated much concern due to its toxic effects therefore, it is necessary to degrade this dye from waste water.<smiles>CN(C)c1ccc(C(=C2C=CC(=[N+](C)[O-])C=C2)c2ccccc2)cc1</smiles>

Fig. 1 Structure of malachite green

Nanoparticles of titanium dioxide co-doped with carbon and iron (III) were prepared by Lavanda et al. [1] via the microemulsion method. It was reported that doped $\mathrm{C}$ atoms exist as the $\mathrm{O}-\mathrm{Ti}-\mathrm{C}$ structure or interstitial $\mathrm{C}$ in $\mathrm{TiO}_{2}$ lattice, whereas the doped $\mathrm{Fe}^{3+}$ atoms substitute some of $\mathrm{Ti}^{4+}$ to form the $\mathrm{Ti}-\mathrm{O}-\mathrm{Fe}$ structure. It was reported that as-prepared $\mathrm{C}$, Fe codoped $\mathrm{TiO}_{2}$ samples exhibited a narrow band gap and stronger visible light absorption. The photocatalytic activity in the visible light region was enhanced on co-doping $\mathrm{TiO}_{2} \mathrm{NPs}$ as it inhibited the electron-hole recombination. It was revealed that co-doped with $\mathrm{C}$ and $2.01 \mathrm{wt} \% \mathrm{Fe}$ showed excellent photocatalytic activity and its degradation efficiency for malachite green was also improved by $78 \%$ under visible light irradiation as compared to pure $\mathrm{TiO}_{2}$. $\mathrm{Bi}_{2} \mathrm{WO}_{6}$ photocatalyst was utilized by Chen et al. [2] to degrade malachite green. The effects of the concentration of malachite green, $\mathrm{pH}$, and the concentration of $\mathrm{Bi}_{2} \mathrm{WO}_{6}$ on the photocatalytic efficiency were investigated. Amar et al. [3] synthesized Cadoped ceria (CDC) via co-precipitation method. They used ammonium oxalate as a precipitating agent. The band gap of CDC was found to be 3.96 $\mathrm{eV}$. Various rate affecting parameters were evaluated such as irradiation time, photocatalyst dosage, initial dye concentration, and temperature on photodegradation of malachite green. It was revealed that CDC could

degrade about $93 \%$ of malachite green dye at the optimum conditions. They are the concentration of dye as $6 \mathrm{mgL}^{-1}$, irradiation time of $90 \mathrm{~min}$, photocatalyst of $0.1 \mathrm{~g}$, and at temperature $35^{\circ} \mathrm{C}$.

Magnetic photocatalyst nanoparticles with the nanocomposite structures of $\mathrm{Fe}_{3} \mathrm{O}_{4} @ \mathrm{TiO}_{2}$ (FT) and $\mathrm{Fe}_{3} \mathrm{O}_{4} @ \mathrm{SiO}_{2} @ \mathrm{TiO}_{2}$ (FST) were prepared by Farhadian and Kazemzad [4]. It was reported that core-shell nanoparticles are formed. The degradation of malachite green was carried out in presence of these samples, which showed that FST sample has better photocatalytic activity as compared to FT samples. It was also observed that high degradation efficiency of $87 \%$ was retained by FST nanoparticles even after five cycles of utilization. Bansal et al. [5] reported the photocatalytic degradation of malachite green, in the presence of photocatalysts titanium dioxide, zinc oxide, and their different ratios. The rate of decolorization was monitored spectrophotometrically. The effect of different process parameters such as $\mathrm{pH}$ (2-9), initial concentration of dye (5-50 ppm) and amount of catalyst $\left(0.5-1.5 \mathrm{gL}^{-1}\right)$ on degradation of the dye was also observed. It was reported that maximum degradation of dye occurred in acidic range with $\mathrm{TiO}_{2}$ and at neutral $\mathrm{pH}$ with $\mathrm{ZnO}$. However, best results were obtained with $\mathrm{ZnO}$ and $\mathrm{TiO}_{2}$, when mixed in the ratio of 9:1. Niobium oxide was used as a photocatalyst by Hussein and Fairooz [6] to degrade the industrial malachite green dye. They studied the effect of different factors for photodegradation such as catalyst (0.03-0.3 g), initial concentration of dye $(5-15) \mathrm{ppm}$, temperature $\left(5-25^{\circ} \mathrm{C}\right)$, light intensity $\left(2.3-3.5 \mathrm{~mW} \mathrm{~cm}^{-2}\right), \mathrm{pH}(2-8)$, hydrogen peroxide $(0.5-2 \mathrm{~mL})$ and type of gas (air, $\mathrm{N}_{2}$ ).

Nanocube structure of sodium niobite was prepared by Baeissa [7] using a hydrothermal method. These nanocubes were doped with gold by impregnation with an aqueous solution of $\mathrm{HAuCl}_{4}$. The band gap of sodium niobate was decreased from $3.4 \mathrm{eV}$ to $2.45 \mathrm{eV}$ on gold doping. The photocatalytic performance of as-prepared photocatalyst was studied in degradation of malachite green using visible light irradiation. It was revealed that the photocatalytic performance of gold-doped sodium niobate was higher than that of sodium niobate as well as $\mathrm{TiO}_{2}$ Degussa under visible light. Photocatalytic activity of ZnO-NPs was tested by Sukri et al. [8] for degradation of malachite green under UV light irradiation. These ZnO-NPs were biosynthesized using Punicagranatum (pomegranate) fruit peels extract as the stabilizing agent. A sol-gel method was used and calcination at different temperatures was carried out to obtain pure ZnO-NPs with higher photocatalytic properties. The $20 \mathrm{mg}$ $\mathrm{ZnO}$-NPs were used to degrade malachite green $(10 \mathrm{ppm}$ initial concentration) for $50 \mathrm{~min}$. It was revealed that $\mathrm{ZnO}$-NPs calcined in $700{ }^{\circ} \mathrm{C}$ showed highest removal efficiency of about $99 \%$ in $40 \mathrm{~min}$. The crossed 
beam pulsed laser deposition technique was successfully used by Alvarez et al. [9] to prepare $\mathrm{Co}: \mathrm{TiO}_{2}$ thin films with different cobalt concentrations. Its band gap was estimated to be $2.0 \mathrm{eV}$. The $\mathrm{TiO}_{2}$ thin films modified with different amounts of cobalt $\left(\mathrm{Co}\right.$ : $\left.\mathrm{TiO}_{2}\right)$ were used as catalysts in the degradation of malachite green as well as solutions containing same pharmaceutical wastes like analgesics diclofenac and naproxen. The UV lamp with emission at 254 and $404 \mathrm{~nm}$ was used as the light energy source. It was claimed that samples containing cobalt exhibited better photocatalytic performance as compared to undoped $\mathrm{TiO}_{2}$ films.

Magdalane et al. [10] synthesized $\mathrm{CeO}_{2} / \mathrm{CdO}$ multi-layered nanoplatelet arrays using sol-gel method at two different temperatures. They used Citrus limonum fruit extract for this purpose. It was revealed that platelet shaped arrays with an average size of $10 \mathrm{~nm}$ were obtained. It was reported that both; the hole $\left(\mathrm{h}^{+}\right)$and hydroxyl radical $(\cdot \mathrm{OH})$ played a major role than the superoxide radical in malachite green degradation. Nickel vanadate was prepared and used as a photocatalyst by Rathore et al. [11]. It was then used for degradation of malachite green. Superoxide anion radical was proposed as responsible species for degradation of the dye molecules. The reaction parameters were optimized for this degradation and these were: $\mathrm{pH}=9.5$, [Malachite green] $=1.00 \times 10^{-5} \mathrm{M}$, nickel vanadate $=0.10 \mathrm{~g}$ and light intensity $=50.0 \mathrm{mWcm}^{-2}$. Ni/MgFe $\mathrm{O}_{4}$ (NMF) nanocomposite were synthesized by Abilarasu et al. [12] via solution combustion method. Later it was tested for photocatalytic degradation of malachite green dye under visible light. It was revealed that NMF showed cubic spinel structure as evident from powder X-ray diffraction. It was having flakes like structure. As-prepared nanoparticles showed higher sunlight driven photocatalytic activity. The mineralization of malachite green was confirmed based on COD measurements.

A facile solid state metathesis synthesis of copper tungstate $\left(\mathrm{CuWO}_{4}\right)$ was reported by Medidi et al. [13], followed by ball milling and preparation of copper tungstate-graphene oxide $\left(\mathrm{CuWO}_{4}\right.$-GO) nanocomposite using a colloidal blending process. Then, copper tungstate-graphene oxide nanocomposites have been used for the photocatalytic degradation of malachite green under visible light irradiation. It was observed that band gap was $2.13 \mathrm{eV}$ and it increases range and intensity of light absorption as well as reduction of electron-hole pair recombination in $\mathrm{CuWO}_{4}$ by introducing GO in it. Malachite green is a toxic dye and effluents containing malachite green from dyeing, printing, and textile industries are left in nearby water streams, sometimes untreated or partially treated. Its degradation is necessary to make that water useful. Although various methods of treatment are there, but each one of them has some or the other demerit. It is therefore necessary to search for an alternate method of degrading malachite green by an eco-friendly method. Here, photocatalysis is useful, which is an advanced oxidation process. In the present work, calcium molybdate has been selected as a photocatalyst and it was doped with carbon to enhance its photocatalytic activity.

\section{Experimental Methods}

\subsection{Chemicals Used}

Malachite green (Himedia), ammonium molybdate (Thermo Fischer), calcium chloride (Merck), and glucose (Thermo Fischer) were used in present investigations. Double distilled water was used to prepare all solutions.

\subsection{Preparation of Photocatalysts}

Undoped calcium molybdate and carbon-doped calcium molybdates were synthesized as reported earlier [14]. Undoped calcium molybdate

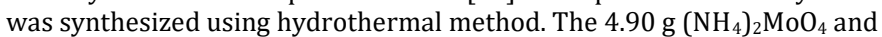
$3.66 \mathrm{~g} \mathrm{CaCl}_{2} .2 \mathrm{H}_{2} \mathrm{O}$ was dissolved in $10 \mathrm{~mL}$ distilled water separately with continuous stirring and named as solution A and solution B, respectively. Solution B was slowly added in solution A under vigorous stirring for 30 min. Few drops of aqueous $\mathrm{NaOH}(1 \mathrm{~N})$ were added and then reaction mixture was kept in a Teflon coated autoclave at $200^{\circ} \mathrm{C}$. White precipitates were obtained. These were filtered, washed with water and dried at $80^{\circ} \mathrm{C}$. Then resulting solid was calcined for $3 \mathrm{~h}$ at $200^{\circ} \mathrm{C}$. Carbon-doped calcium molybdates (1, 2 and 3\%) were synthesized by adding $0.125,0.25$ and $0.375 \mathrm{~g}$ per $10 \mathrm{~mL}$ glucose solution in $10 \mathrm{~mL}$ distilled water separately to the reaction mixture containing ammonium molybdate and calcium chloride. Then few drops of aqueous $\mathrm{NaOH}$ solution $(1 \mathrm{~N})$ was added. The solution was heated up to $200{ }^{\circ} \mathrm{C}$ for $90 \mathrm{~min}$, then filtered, washed with water and dried at $80^{\circ} \mathrm{C}$.

\subsection{Photocatalytic Degradation}

Initially few control experiments were carried out to get approximate optimum parameters. Then, $25 \mathrm{~mL}$ of dye solution $\left(1.0 \times 10^{-3} \mathrm{M}\right)$ was taken https://doi.org/10.30799/jacs.237.21070202 in volumetric flask of $250 \mathrm{~mL}$ capacity. The solution was diluted with distilled water so that the concentration of dye solution became $1.0 \times 10^{-4}$ $M$. The solution was divided in to four equal parts. In the first beaker, only dye solution was taken and kept in the dark. In the second beaker, only dye solution was taken and exposed to the light. In the third beaker, $0.10 \mathrm{~g}$ undoped calcium molybdate or C-doped (1, 2 or $3 \%$ ) calcium molybdate (photocatalyst) was added to the dye solution and kept in dark. In the fourth beaker, $0.10 \mathrm{~g}$ undoped calcium molybdate or C-doped $(1,2$ or $3 \%)$ calcium molybdate (photocatalyst) was added to the dye solution and exposed to the light. After few hours, the absorbance of the solution in each beaker was measured with the help of a spectrophotometer. It was found that the solutions of the first three beakers in each case had almost the same absorbance as initial absorbance, while absorbance of reaction mixture in fourth beaker in each case had considerable decrease in absorbance as compared to its initial value, indicating that undoped calcium molybdate or C-doped (1, 2 and 3\%) calcium molybdate and light both are necessary for degradation of dye. Hence, this was concluded that the reaction is photocatalytic in nature and not chemical and photochemical. Hence the further subsequent degradation studies were carried out with undoped calcium molybdate or C-doped (1, 2 and 3\%) calcium molybdate in presence of light.

\section{Results and Discussion}

\subsection{Characterization of Catalysts}

\subsubsection{Field Emission Scanning Electron Microscopy (FESEM) Study}

The morphology of the particles were examined using Field Emission Scanning Electron Microscope (Nova NanoSEM, model) operated at a voltage of $15 \mathrm{kV}$. The microstructural characterization of undoped $\mathrm{CaMoO}_{4}$ and $\mathrm{C}$-doped $\mathrm{CaMoO}_{4} 1 \%$ were carried out via field emission scanning electron microscopy. The FESEM images of the undoped $\mathrm{CaMoO}_{4}$ and $\mathrm{C}$ doped $\mathrm{CaMoO}_{4}(1 \%)$ (glucose was used as $\mathrm{C}$ source) are presented in Fig. 2. It was observed that particles of undoped $\mathrm{CaMoO}_{4}$ were spherical in shape while on $\mathrm{C}$-doping, the particles of $\mathrm{CaMoO}_{4}$ for $1 \% \mathrm{C}$-doped $\mathrm{CaMoO}_{4}$ formed clusters.
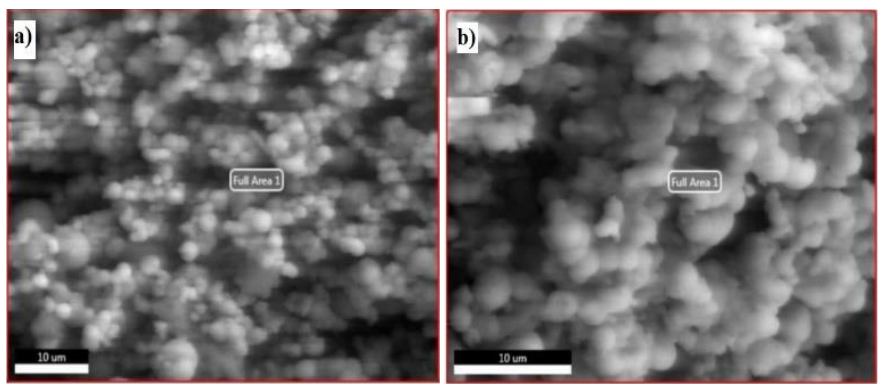

Fig. 2 FE-SEM images of (a) undoped $\mathrm{CaMoO}_{4}$ and (b) $1 \%$ C-doped $\mathrm{CaMoO}_{4}$

\subsubsection{Energy Dispersive X-Ray Analysis (EDX)}

EDX analysis was performed to study the chemical composition of the samples. EDX spectra of undoped $\mathrm{CaMoO}_{4}$, and C-doped $\mathrm{CaMoO}_{4}(1 \%)$ are presented in Figs. 3 and 4, respectively The analysis results show that the undoped sample was containing $25.11 \% \mathrm{Ca}, 47.36 \%$ Mo and $26.53 \%$ O. An estimation of carbon content in C-doped $\mathrm{CaMoO}_{4}$ was also obtained from EDX measurements. It is clear from these figures that undoped $\mathrm{CaMoO}_{4}$ contains only $\mathrm{Ca}$, Mo and $\mathrm{O}$ and no other impurity. Hence, it is pure $\mathrm{CaMoO}_{4}$. But in case of carbon doped $\mathrm{CaMoO}_{4}$, the peaks for carbon were also observed in EDX.

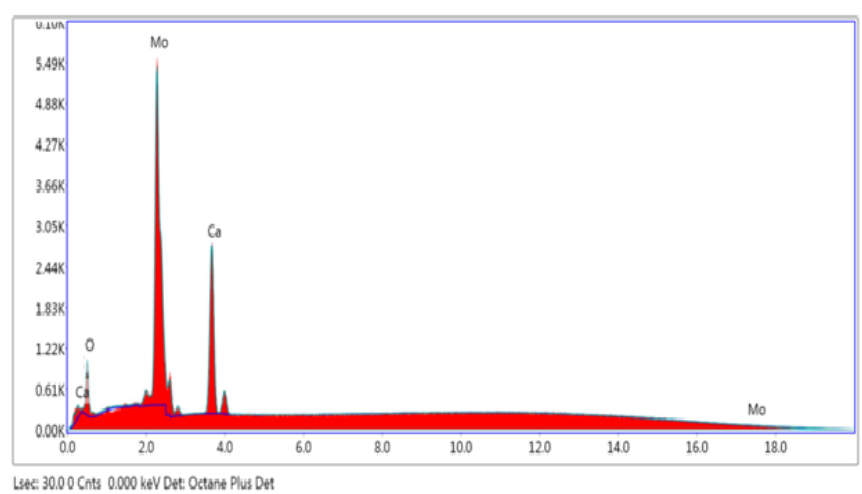

Fig. 3 EDX image of undoped $\mathrm{CaMoO}_{4}$ 


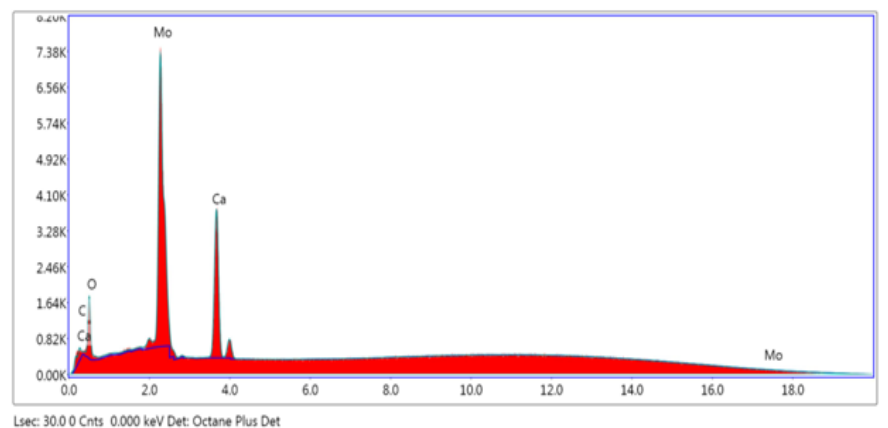

Fig. 4 EDX image of C-doped (1\%) $\mathrm{CaMoO}_{4}$

\subsubsection{X-Ray Diffraction Analysis (XRD)}

The crystal size of as-prepared $\mathrm{CaMoO}_{4}$ composite was determined by the X-ray diffractometer (XRD) (Panalytical X Pert Pro) using CuKa radiation $(\lambda=1.54 \mathrm{~nm})$ in the $2 \theta$ scanning ranges from $20^{\circ}$ to $80^{\circ}$ with a scan rate at $10^{\circ} \mathrm{min}^{-1}$. The applied voltage and current were $40 \mathrm{KV}$ and 40 $\mathrm{mA}$, respectively. The powder XRD pattern of as-prepared $\mathrm{CaMoO}_{4}$ composite and C-doped $\mathrm{CaMoO}_{4}(1 \%)$ are given in Figs. 5 and 6 respectively.

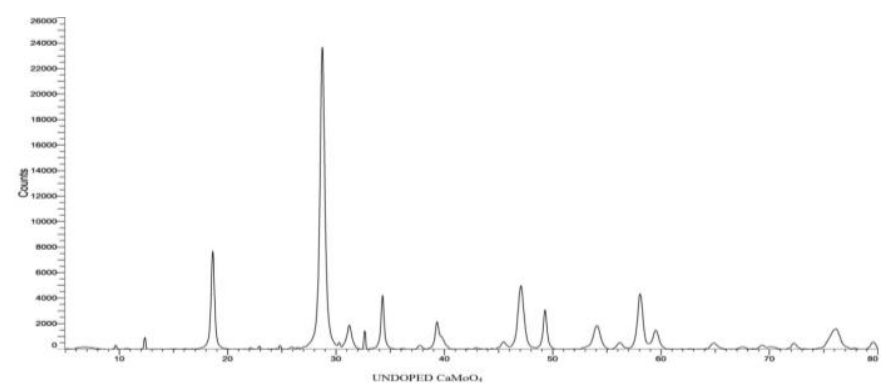

Fig. 5 XRD of undoped $\mathrm{CaMoO}_{4}$

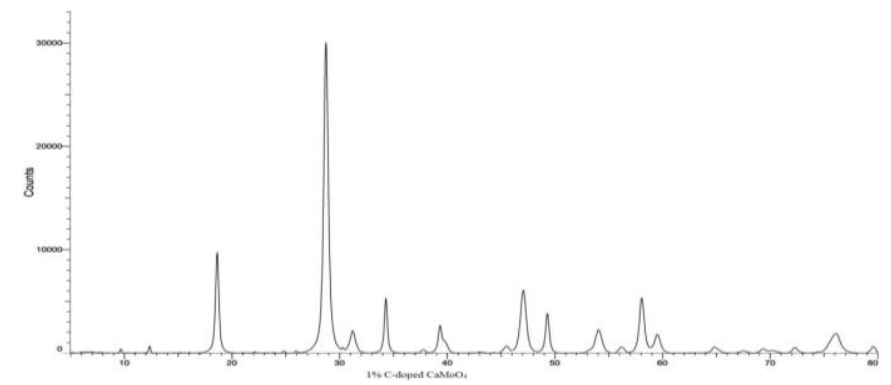

Fig. 6 XRD of $1 \%$ C-doped $\mathrm{CaMoO}_{4}$

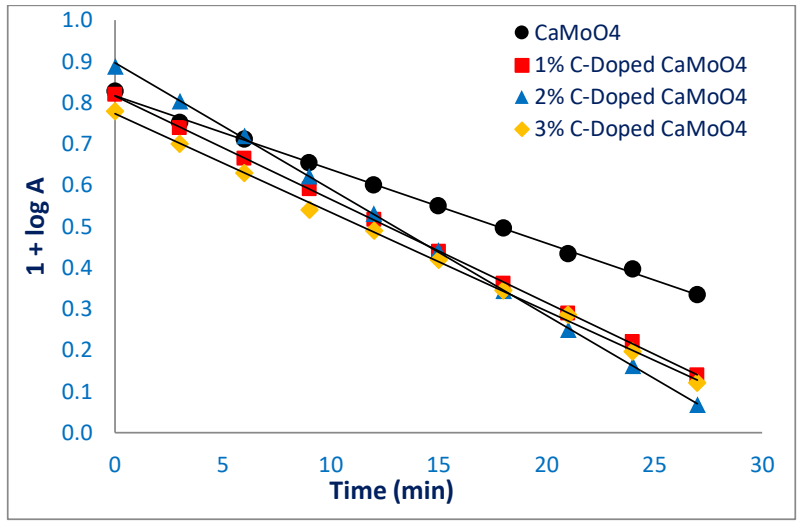

Fig. 7 Typical runs of degradation of malachite green

\subsection{Degradation Study}

$0.0365 \mathrm{~g}$ of malachite green was dissolved in $100 \mathrm{~mL}$ of doubly distilled water, so that the concentration of dye solution was $1.0 \times 10^{-3} \mathrm{M}$. It was used as a stock solution. This solution was further diluted to required concentrations. $50 \mathrm{~mL}$ dye solution of $5.00 \times 10^{-4} \mathrm{M}$ concentration was taken in a beaker. The $\mathrm{pH}$ of this solution was adjusted to 9.7 and $0.12 \mathrm{~g}$ of catalyst $\mathrm{CaMoO}_{4}$ was added in it. Now this reaction mixture was exposed to a $200 \mathrm{~W}$ tungsten lamp. A water filter was used to cut off thermal radiations. An aliquot of $3 \mathrm{~mL}$ was taken out from the reaction mixture at https://doi.org/10.30799/jacs.237.21070202 regular time intervals and its absorbance (A) was observed at $617 \mathrm{~nm}$. It was observed that the absorbance decreases with increasing time of exposure. A plot of $1+\log$ A versus time was found to be linear. It shows that the reaction follows pseudo-first order kinetics. The rate constant was calculated by the rate expression, $\mathrm{k}=2.303 \mathrm{x}$ Slope. The same procedure was followed using catalyst $1 \%, 2 \%$ and $3 \% \mathrm{C}$-doped $\mathrm{CaMoO}_{4}$. The results of typical runs for photocatalytic degradation of malachite green using catalysts $\mathrm{CaMoO}_{4}$ and 1, 2 and 3\% C-doped $\mathrm{CaMoO}_{4}$ are shown in Fig. 7.

\subsubsection{Effect of $p H$}

The effect of $\mathrm{pH}$ on the rate of degradation was investigated in $\mathrm{pH}$ range 8.2-10.0 for undoped and 1, 2 and $3 \% \mathrm{C}$-doped $\mathrm{CaMoO}_{4}$, keeping all other parameters identical. The results are summarized in Table 1 . It was observed that with an increase in $\mathrm{pH}$, rate of reaction increases. After attaining the maximum value at $\mathrm{pH} 9.7$ for undoped, 2 and 3\% C-doped $\mathrm{CaMoO}_{4}$, and 9.4 for $1 \% \mathrm{C}$-doped $\mathrm{CaMoO}_{4}$ respectively, rate decreases with a further increase in $\mathrm{pH}$. In this case, the presence of scavenger i.e., 2propanol affect the rate of reaction adversely and hence, it may be concluded that $\cdot \mathrm{OH}$ radicals participate in the degradation as an active oxidizing species.

Table 1 Effect of pH ([Malachite Green $]=5.00 \times 10^{-4} \mathrm{M}$; Amount of photocatalyst = $0.12 \mathrm{~g}$; Light intensity $=50.0 \mathrm{mWcm}^{-2}$ )

\begin{tabular}{lllll}
\hline pH & \multicolumn{4}{l}{ Rate constant $(\mathrm{k}) \times 10^{5}\left(\mathrm{sec}^{-1}\right)$} \\
\cline { 2 - 5 } & $\mathrm{CaMoO}_{4}$ & $1 \% \mathrm{C}$-Doped & $2 \%$ C-Doped & $3 \%$ C-Doped \\
\hline 8.2 & 5.46 & 6.88 & 7.33 & 5.22 \\
8.5 & 6.92 & 7.43 & 8.20 & 6.16 \\
8.8 & 7.37 & 8.12 & 9.48 & 7.02 \\
9.1 & 8.00 & 9.06 & 10.27 & 8.33 \\
9.4 & 8.71 & 9.78 & 11.01 & 9.05 \\
9.7 & 9.37 & 9.66 & 11.60 & 9.45 \\
10.0 & 8.02 & 8.14 & 10.14 & 8.97 \\
\hline
\end{tabular}

\subsubsection{Effect of Dye Concentration}

The effect of variation of concentration of malachite green on its degradation rate has been observed in the range from $4.4 \times 10^{-4}$ to $5.8 \times$ $10^{-4} \mathrm{M}$ for undoped and 1-3\% C-doped $\mathrm{CaMoO}_{4}$ keeping all other parameters same. The results are given in Table 2 . It has been observed that the rate of degradation increases with increasing concentration of dye up to $5.0 \times 10^{-5} \mathrm{M}$ for undoped and 1-3\% C-doped $\mathrm{CaMoO}_{4}$. Further increase in concentration beyond this limit results in a decrease in degradation rate. This may be explained on the basis that on increasing the concentration of dye, the reaction rate increases as more molecules of dyes were available. A decreasing in rate of degradation may be due to the fact that after a particular concentration, the dye may start acting as an internal filter itself and it will not permit the sufficient light intensity to reach the surface of the photocatalyst at the bottom of reaction vessel.

Table 2 Effect of dye concentration $) \mathrm{pH}=9.7$; Amount of photocatalyst $=0.12 \mathrm{~g}$; Light intensity $=50.0 \mathrm{mWcm}^{-2}$ )

\begin{tabular}{lllll}
\hline Malachite Green] & \multicolumn{5}{l}{ Rate constant $(\mathrm{k}) \times 10^{5}\left(\mathrm{sec}^{-1}\right)$} \\
\cline { 2 - 5 }$\times 10^{4} \mathrm{M}$ & $\mathrm{CaMoO}_{4}$ & $1 \% \mathrm{C}$-Doped & $2 \%$ C-Doped & $3 \%$ C-Doped \\
\hline 4.4 & 5.77 & 5.92 & 6.44 & 5.24 \\
4.6 & 7.04 & 7.15 & 8.37 & 6.98 \\
4.8 & 8.11 & 8.23 & 10.24 & 8.77 \\
5.0 & 9.37 & 9.78 & 11.60 & 9.45 \\
5.2 & 9.04 & 9.21 & 10.04 & 8.95 \\
5.4 & 8.18 & 8.05 & 9.13 & 7.42 \\
5.6 & 7.00 & 6.96 & 8.06 & 6.26 \\
5.8 & 5.29 & 5.45 & 6.78 & 5.78 \\
\hline
\end{tabular}

\subsubsection{Effect of Amount of Photocatalyst}

The effect of variation of the amount of photocatalyst on the rate of dye degradation has been observed in the range from 0.06 to $0.15 \mathrm{~g}$ and the results are reported in Table 3 . It has been observed that with an increase in the amount of photocatalyst, the rate of degradation increases to a certain amount of photocatalyst i.e. $0.12 \mathrm{~g}$, for undoped as well as $1 \%, 2 \%$ and $3 \% \mathrm{C}$-doped $\mathrm{CaMoO}_{4}$. Beyond this point, the rate of reaction becomes virtually constant with an increase in the amount of photocatalyst. This behaviour may be explained on the basis that with an increase in the amount of photocatalyst, the exposed surface area of catalyst will increase. Hence, the rise in the rate of reaction has been observed, but with further increase in the amount of photocatalyst beyond a limit, only thickness of the layer (and not the exposed surface area) will increase at the bottom of reaction vessel, which was completely covered by the photocatalyst. Therefore, saturation like behavior is observed. 
Table 3 Effect of amount of photocatalyst ([Malachite Green] $=5.00 \times 10^{-4} \mathrm{M} ; \mathrm{pH}=$ 9.7; Light intensity $=50.0 \mathrm{mWcm}^{-2}$ )

\begin{tabular}{lllll}
\hline Photocatalyst (g) & \multicolumn{5}{l}{ Rate constant $(\mathrm{k}) \times 10^{5}\left(\mathrm{sec}^{-1}\right)$} \\
\cline { 2 - 5 } & $\mathrm{CaMoO}_{4}$ & $1 \%$ C-Doped & $2 \%$ C-Doped & $3 \%$ C-Doped \\
\hline 0.06 & 5.11 & 6.14 & 7.43 & 6.12 \\
0.08 & 7.05 & 7.65 & 8.99 & 7.47 \\
0.10 & 8.24 & 8.90 & 10.02 & 8.96 \\
0.12 & 9.37 & 9.78 & 11.60 & 9.45 \\
0.13 & 9.16 & 9.78 & 11.61 & 9.45 \\
0.14 & 9.17 & 9.78 & 11.60 & 9.47 \\
0.15 & 9.17 & 9.76 & 11.61 & 9.45 \\
\hline
\end{tabular}

\subsubsection{Effect of Light Intensity}

The effect of light intensity on the rate of degradation of dye was also studied by varying the intensity of light from 20.0 to $70.0 \mathrm{mWcm}^{-2}$. The observations are presented in Table 4. The data indicate that with increasing light intensity, the rate of reaction increases and maximum rates were found at $50.0 \mathrm{~mW} \mathrm{~cm}^{-2}$ for undoped and 1-3\% C-doped $\mathrm{CaMoO}_{4}$. It may be explained on the basis that as the light intensity was increased, the number of photons striking per unit time per unit area also increases, resulting in higher rate of degradation. Further increase in the light intensity may start some thermal side reactions and hence, higher intensities of light have been avoided.

Table 4 Effect of light intensity ([Malachite Green $]=5.00 \times 10^{-4} \mathrm{M} ; \mathrm{pH}=9.7$; Amount of photocatalyst $=0.12 \mathrm{~g}$ )

\begin{tabular}{lllll}
\hline \multirow{2}{*}{$\begin{array}{l}\text { Light Intensity } \\
\left(\mathrm{mW} \mathrm{cm}{ }^{-2}\right)\end{array}$} & \multicolumn{4}{l}{ Rate constant $(\mathrm{k}) \times 10^{5}\left(\mathrm{sec}^{-1}\right)$} \\
\cline { 2 - 5 } & $\mathrm{CaMoO}_{4}$ & $1 \% \mathrm{C}$-Doped & $2 \%$ C-Doped & $3 \%$ C-Doped \\
\hline 20.0 & 6.04 & 6.98 & 7.33 & 6.77 \\
30.0 & 7.12 & 8.11 & 9.10 & 7.94 \\
40.0 & 8.76 & 9.04 & 10.25 & 9.01 \\
50.0 & 9.37 & 9.78 & 11.60 & 9.45 \\
60.0 & 9.02 & 9.43 & 11.04 & 9.12 \\
70.0 & 8.88 & 8.90 & 10.76 & 8.48 \\
\hline
\end{tabular}

\subsection{Proposed Mechanism}

On the basis of experimental observations, the following tentative mechanism has been suggested for photocatalytic degradation of malachite green.

$\begin{array}{lll}{ }^{1} \mathrm{MG}_{0} & \stackrel{\mathrm{h} v}{\longrightarrow} & { }^{1} \mathrm{MG}_{1} \\ { }^{1} \mathrm{MG}_{1} & \stackrel{\mathrm{ISC}}{\longrightarrow} & { }^{3} \mathrm{MG}_{1} \\ \mathrm{SC} & \stackrel{\mathrm{h} v}{\longrightarrow} & \mathrm{e}^{-}(\mathrm{CB})+\mathrm{h}^{+}(\mathrm{VB}) \\ \mathrm{h}^{+}+\mathrm{OH}^{-} & \longrightarrow & \cdot \mathrm{OH} \\ \cdot \mathrm{OH}+{ }^{3} \mathrm{MG}_{1} & \longrightarrow & \text { Leuco-MG } \\ \text { Leuco-MG } & \longrightarrow & \text { Products }\end{array}$

where, $\mathrm{MG}=$ Malachite green and SC (Semiconductor) $=\mathrm{CaMoO}_{4}$ (Undoped as well as 1,2 and 3\% carbon-doped).

First of all, malachite green absorbs radiation of suitable wavelength and it is excited to its first excited singlet state, which then goes to its triplet excited state through intersystem crossing. Calcium molybdate also absorbs light to excite electron from valence band to conduction band leaving a hole in valence band. This hole is electron deficient and medium is alkaline (more $\mathrm{OH}^{-}$ions); therefore, an electron is abstracted from hydroxyl ions to generate hydroxyl radicals). These radicals are strong oxidant and non-selective and therefore, they will attack triplet state of malachite green converting it into its leuco (colorless) form, which is unstable and it will degrade to some smaller almost harmless products like carbon dioxide, water, $\mathrm{NO}_{3}^{-}$and $\mathrm{Cl}^{-}$ion.

\section{Conclusion}

The malachite green can be degraded photocatalytically in the presence of undoped as well as $1-3 \%$ carbon-doped $\mathrm{CaMoO}_{4}$. It was found that photocatalytic activity of $\mathrm{CaMoO}_{4}$ increases on carbon doping and the maximum rate of degradation were found with $2 \% \mathrm{C}$-doped $\mathrm{CaMoO}_{4}$ but there was slight adverse effect on increasing the amount of carbon dopant above this value. The optimum conditions for degradation of malachite green are found to be $\mathrm{pH} 9.7$, concentration of dye as $5.00 \times 10^{-5} \mathrm{M}, 0.12 \mathrm{~g}$ of photocatalyst and light intensity as $50.0 \mathrm{~mW} \mathrm{~cm}^{-2}$.

\section{Acknowledgment}

Authors are thankful to Head, Department of Chemistry, PAHER University, Udaipur for providing necessary laboratory facilities and SICART, Vallabh Vidhyanagar, Gujarat for recording FESEM, EDX and XRD.

\section{References}

[1] B. Lavanda, M.N. Bhatub, Y.S. Malghe, Visible light photocatalytic degradation of malachite green using modified titania, J. Mater. Res. Technol. 8(1) (2019) 299-308.

[2] Y. Chen, Y. Zhang, C. Liu, A. Lu, W. Zhang, Photodegradation of malachite green by nanostructured $\mathrm{Bi}_{2} \mathrm{WO}_{6}$, Visible light-induced photocatalyst, Int. J. Photoener. 2012(1) (2011) 1-6.

[3] I.A. Amar, H.M. Harara, Q.A. Baqul, M.A.A. Qadir, F.A. Altohami, M.M. Ahwidi, Photocatalytic degradation of malachite green dye under UV light irradiation using calcium-doped ceria nanoparticles, Asian J. Nanosci. Mater. 3(1) (2020) $1-14$.

[4] M. Farhadian, M. Kazemzad, Photocatalytic degradation of malachite green by magnetic photocatalyst, Synth. React. Inorg. M 46(3) (2015) 458-463.

[5] P. Bansal, N. Bhullar, D. Sud, Studies on photodegradation of malachite Green using TiO2/ZnO photocatalyst, Desalin. Water Treat. 12(3) (2009) 108-113.

[6] A.S. Hussein, N.Y. Fairooz, Photocatalytic degradation of malachite green dye over naked niobium oxide as a photocatalyst, J. Babylon Univ. Pure App. Sci. 24(9) (2016) 2510-2518.

[7] E.S. Baeissa, Photocatalytic degradation of malachite green dye using $\mathrm{Au} / \mathrm{NaNbO}_{3}$ nanoparticles, J. Alloys Compd. 672 (2016) 2510-2518.

[8] S.N.A.M. Sukri, E.D.M. Isa, K. Shameli, Photocatalytic degradation of malachite green dye by plant-mediated biosynthesized zinc oxide, IOP Conf. Ser. Mater Sci. Eng. 808 (2019) 012034.

[9] J.P. Alvarez, D.A.S. Casados, S. Romero, L.E. Alarcón, Photocatalytic degradation of malachite green dye and pharmaceuticals using $\mathrm{Co}: \mathrm{TiO}_{2}$ thin films, Adv. Mater. Res. 976 (2014) 212-216.

[10] C.M. Magdalane, K. Kaviyarasu, J.J. Vijaya, C. Jayakumar, M. Maaza, B. Jeyaraj, Photocatalytic degradation effect of malachite green and catalytic hydrogenation by UV-illuminated $\mathrm{CeO}_{2} / \mathrm{CdO}$ multilayered nanoplatelet arrays: Investigation of antifungal and antimicrobial activities, J. Photochem. Photobiol. B 169 (2017) 110-123.

[11] R. Rathore, R. Ameta, S.C. Ameta, Photocatalytic degradation of malachite green over nickel vanadate powder, Acta Chim. Pharm. Indica 4(4) (2014) 213-220.

[12] A. Abilarasu, T. Somanathan, A. Saravanan, V. Saravanan, P. Rajakumar, Enhanced photocatalytic degradation of malachite green on spinel ferrite (nickel/ magnesium ferrite) under direct sun light, Int. J. Pharm. Biol. Sci. 7(4) (2016) 93-99.

[13] S. Medidi, S. Markapurapu, M.R. Kotupalli, R.K.R. Chinnam, V.M. Susarla, H.B. Gandham, et al, Visible light photocatalytic degradation of methylene blue and malachite green dyes with $\mathrm{CuWO}_{4}-\mathrm{GO}$ nano composite, Chem. Mater. Sci. 7(2) (2018) 17-34.

[14] H.S. Chawda, Avinash K. Rai, R. Rathore, Suresh C. Ameta, R. Ameta, Undoped and carbon-doped calcium molybdate as photocatalyst for degradation of methylene blue, J. Ind. Chem. Soc. 97(11) (2020) 2397-2406. 